\title{
El Lunfardo en la Evolución del Español ARGENTINO*
}

\author{
Gerardo Augusto Lorenzino**
}

\section{Resumen}

En este artículo se analizarán informes contemporáneos de periódicos, así como estudios criminológicos y sociológicos basados en la vida del submundo de Buenos Aires, Argentina desde la década de 1870 hasta comienzos de 1900 para evaluar la relación del lunfardo con el lenguaje del hampa, así como el español imperfecto de los inmigrantes italianos, y su influencia en la evolución del español argentino.

Palabras clave: dialecto, lunfardo, español argentino, contacto lingüístico.

\section{Lunfardo in the Evolution of Argentine Spanish}

\begin{abstract}
In this paper, contemporary newspaper reports as well as criminological and sociological studies concerned with the life of the underworld in Buenos Aires, Argentina from the 1870s to the early 1900s will be analyzed to assess the association of lunfardo with the speech of the criminal as well as the imperfect Spanish spoken by Italian immigrants, and their influence in the development of Argentine Spanish.
\end{abstract}

Keywords: dialect, lunfardo, Argentine Spanish, language contact.

Recibido: 01-02-2016

Aceptado: 16-06-2016

* Este artículo es parte del Proyecto de Investigación Social and geographical mobility in the evolution of Argentine Spanish. El autor agradece a Temple University el apoyo del año sabático (2015-16) que le permitió realizar la investigación. También agradece a la Licenciada Marisa Saino la valiosa colaboración prestada en la traducción del texto.

** Argentino. Doctor en Lingüística de la City University of New York (CUNY, Graduate Center). Académico de la Temple University, Filadelfia, EE.UU. galorenz@temple.edu 


\section{Introducción}

Durante el último cuarto del siglo XIX, la vida del inframundo de Buenos Aires inspiró la publicación de crónicas policiales en diarios y monografías criminológicas. Estas son las primeras referencias al lunfardo, toda clase de delincuentes escondiéndose en los tugurios urbanos, arrabales o los bajo fondos de Buenos Aires cuya población estaba experimentando una rápida evolución debido a la creciente inmigración europea.

Los diferentes tipos de ladrones -los carteristas o punguistas, los ladrones de casas o escruchantes y los criminales violentos que atacaban a sus víctimas o biabistas- se comunicaban entre sí mediante un discurso críptico llamado lunfardo. El lunfardo ha sido descrito como un lenguaje especializado (o jerga) empleado por sus hablantes para ocultar sus conversaciones a la policía, a sus víctimas y a los testigos con la finalidad de llevar a cabo sus prácticas ilegales. También ha sido descrito como el lenguaje utilizado por los presos en las cárceles de Buenos Aires (ver sección 2).

El origen del lunfardo, entre los que compartieron los conventillos con inmigrantes y criollos, ha sido el escenario aceptado para su aparición desde las primeras referencias a este 'lenguaje de ladrones' aparecidos a mediados de la década de 1870. El hecho de que la gran aldea -tal como era conocida Buenos Aires en aquel momento- fue significativamente transformada por una considerable afluencia de inmigrantes durante el período en que el lunfardo comienza a ser mencionado por los estudiosos, nos lleva a pensar en la asociación entre inmigración y lunfardo como un escenario natural para su formación. En efecto, las relaciones del submundo del lunfardo se ubican dentro de un contexto social en que los inmigrantes especialmente de Italia y España hablaban diferentes lenguas y dialectos de diversas regiones. Además, dadas las afinidades léxicas entre el lunfardo y el actual español porteño, sería prudente considerar los factores sociolingüísticos que subyacen su aparición en el marco más amplio de la dialectología latinoamericana.

En este artículo se analizarán informes contemporáneos de periódicos, así como estudios pioneros en criminología y sociología sobre la vida del submundo en Buenos Aires -desde la década de 1870 hasta comienzos de 1900-a fin de evaluar la estrecha relación lunfardo-lenguaje del hampa. El 
análisis lingüístico se enfocará en el léxico del lunfardo, su composición, su formación, así como la inclusión de elementos propios de las lenguas de los inmigrantes. Específicamente, las variedades de dialectos italianos presentes en la ciudad y el cocoliche de transición -o español imperfectohablado por los inmigrantes italianos proporcionarán el escenario adecuado para la expansión léxica y la aparición de las lenguas de inmigrantes, y se destacará la manera en que el contacto lingüístico se enmarcó en la transformación vivida por la sociedad de Buenos Aires desde finales del siglo XIX.

Al comparar las primeras manifestaciones del lunfardo con el español popular porteño, uno puede interpretar, figurativamente, su evolución léxica como una 'descriminalización' lingüística, al punto de que éste fue siendo progresivamente aceptado por la sociedad argentina. Esta investigación sostendrá que el lunfardo, los sociolectos españoles usados por las clases más bajas y la mezcla hablada por los inmigrantes convergen en las orillas urbanas de Buenos Aires permitiendo el cruce de influencias lingüísticas. Aquí, las viviendas hacinantes o conventillos devinieron en un micro-espacio emblemático, donde argentinos o criollos, inmigrantes europeos y lunfardos convivieron debido a una necesidad económica. En tal sentido, este entorno social dio lugar a una interacción dinámica entre esos diversos grupos favoreciendo la propagación de las palabras, habiendo algunas de ellas eventualmente contribuido a la formación de español popular porteño.

La segunda sección de este estudio describe al corpus de lunfardo que fue utilizado, el cual consta de un total de cinco textos publicados entre 1879 y 1908. La siguiente sección (3) presenta una visión general de los procesos formativos y de las fuentes lingüísticas que componen la matriz de la cual surgió el léxico lunfardo, destacando el impacto de los idiomas de los inmigrantes y del cocoliche. En la cuarta y última sección, la difusión del léxico en el contexto cotidiano del conventillo y el contacto lingüístico entre inmigrantes y criollos nos servirá para explicar la influencia del entrecruzamiento idiomático en el desarrollo del español popular porteño.

\section{El corpus del lunfardo (18791908)}

Esta sección presentará el corpus sobre el cual está basado este estudio, seguido de una discusión acerca de las fuentes léxicas y 
procesos de composición y derivación que contribuyeron al desarrollo del lunfardo. Más allá de las peculiaridades léxicosemánticas discutidas a continuación, lunfardo es en todos sus aspectos (gramática, léxico general) un registro del español. El corpus utilizado en el análisis abarca un período de treinta años (1879 a 1908) e incluye:

- Dos artículos escritos por Benigno Lugones y publicados en el diario La Nación en 1879 con el intrigante título Los beduinos policiales y el eufemístico Los caballeros de la industria, respectivamente.

- Los hombres de presa (1888) de Luis María Drago, un estudio pionero sobre la vida criminal en Buenos Aires.

- Contribución al estudio de la psicología criminal. El idioma del delito (1894), escrito por el criminólogo Ángel Dellepiane. Al igual que Drago, Dellepiane explora las raíces sociales y psicológicas de la criminalidad, pero también representa el primer estudio del lunfardo como argot.

- Una colección de ensayos por José Álvarez (alias Fray Mocho) titulada Memorias de un vigilante (1897).

- La mala vida en Buenos Aires (1908), del criminólogo Eusebio Gómez.

Estos cinco autores (Lugones, Drago, Dellepiane, Álvarez y Gómez) tenían un conocimiento directo del submundo, sus actores, sus modos de funcionamiento y la organización de sus miembros. A pesar de ser estudios que intentaron comprender los rasgos sociales y psicológicos de los lunfardos como 'criminales', también se refirieron a sus formas de comunicación, la jerga criminal. Álvarez y Lugones habían sido policías urbanos antes de convertirse en periodistas en La Nación dedicados a escribir sobre el crimen en Buenos Aires. Álvarez ascendió de rango, alcanzando el puesto de comisario de pesquisas o detective jefe antes de su retiro de la fuerza policial (Álvarez, 1897).

Dellepiane, Drago y Gómez pasaron tiempo en Europa aprendiendo los fundamentos y metodología de la ciencia de la criminología, todos moldeados en la escuela positivista italiana de Cesare Lombroso, Enrico Ferri y Rafael Garofalo, que se centraba en los aspectos físicos y morales de la criminalidad. Ellos escribieron extensamente sobre el tema, entrevistando a policías y a los propios delincuentes en las cárceles de Buenos Aires. 
(1) a. "El procedimiento de esta categoría de lunfardo ha sido referido con toda exactitud por el Comisario Rossi." (Gómez, 1908, p. 91).

b. "El ejemplo anterior [en lunfardo] no es supuesto; es recogido por el que esto escribe en la Penitenciaría de la Capital." (Dellepiane, 1894, p. 51).

c. "Estos datos los debemos a la amabilidad del señor comisario D. Ignacio Socas, que nos facilitó la ocasión de hablar con algunos de los principales y más conocidos lunfardos." (Drago, 1888, p. 110).

El meticuloso uso de cursiva en el vocabulario lunfardo y las notas al pie de página en el corpus ponen de manifiesto la intención de los autores no sólo de explicar términos jergales que de lo contrario no serían comprendidos por ciertos segmentos de la sociedad, sino también para destacar su uso clandestino. Ellos describen detalladamente y, en el caso de los periodistas Álvarez y Lugones de vez en cuando con un toque humorístico, el modus operandi de los ladrones, sus estructuras de organización y cómo ellos consumían sus actividades delictivas, eufemísticamente llamadas trabajos.

(2) "La palabra hurtar es sinónimo de trabajar en la comunidad de lunfardos o ladrones." (Drago, 1888, p. 67).

Cada banda criminal se organizaba de acuerdo a la función de sus miembros:

(3) "Entre reos lunfardos hay cinco grandes familias: los punguistas, o limpiabolsillos; los escruchantes, o abridores de puertas; los que dan la caramayoli o la biaba o sea los asaltantes [...] (Álvarez, 1897, p. 58).

Una variedad de lunfardo sin descriptivos para referirse a las víctimas sería incompleta. La palabra otario se refiere a la distraída víctima del punguista, quien aplica sus habilidades en los atestados viajes en los tranvías y en las calles. Según Lugones, otarios eran 'personas ingenuas, cándidas y sencillas, muy especialmente nuestros paisanos' (La Nación, Abril 6, 1879).

La etimología más convincente de la palabra lunfardo es su derivación del italiano lombardo 'natural de Lombardía', proveniente del dialecto Romanesco, en el cual lombardo significa 'ladrón', tal vez con influencia genovesa (Gobello, 1982, p. 12425). La referencia más temprana que señala a los propios ladrones antes que a su lengua, se encuentra en un 
artículo anónimo titulado 'El dialecto de los ladrones' publicado por el diario La Prensa en 1878 (Conde, 2011, p. 87), el cual fue probablemente aportado por un comisario familiarizado con el lunfardo, tal como lo sugiere la siguiente cita:

(5) "Pero un comisario que se ocupa de hacerle la guerra a los ladrones tiene un vocabulario [del lunfardo] y de este vocabulario hemos tomado la copia de algunas de las frases más usuales." (Op. Cit.).

La Prensa fue uno de los dos principales diarios de Buenos Aires en aquella época; el otro, La Nación, era donde los artículos de Lugones aparecerían un año más tarde (1879 a-b). Es en uno de estos artículos en el que podemos encontrar los primeros testimonios del lunfardo en cuanto lengua del hampa en dos notas. En el primero, él identifica lunfardo con el caló, nombre empleado en España para referirse a la comunicación críptica entre los ladrones, y en el segundo, aporta a los lectores indicaciones para la pronunciación de ciertos sonidos del lunfardo:

(6) a. "Las palabras que en adelante se encuentren subrayadas pertenecen, como lunfardo, al caló de los ladrones."

b. "Pronúnciese en ésta y demás palabras del lunfardo la 'ch' como en la lengua francesa." (La Prensa, 1879).

Como sustantivo, el término aparece en la frase lunfardos extranjeros (La Nación, marzo 18, 1879); como modificador, en poesía lunfarda (Op. Cit.) y mundo lunfardo. En Drago, el doble uso de lunfardo para referirse a ambos, 'delincuentes' y 'lengua', está ya instalado en la literatura:

(7) "En el lunfardo (palabra que designa al mismo tiempo la jerga y los que se valen de ella), de los delincuentes bonaerenses, se nota muchas locuciones cuyo empleo a todas luces revela la necesidad de recurrir en ciertos casos a una jerigonza especial." (1888:102).

Las investigaciones de Dellepiane tenían una visión más amplia al comparar la jerga delictiva porteña con los argots de Francia, Italia y España.

(8) "Los ladrones de profesión. . . se sirven en las relaciones privadas que mantienen entre sí, de un lenguaje especial, enteramente propio [...] que no trasciende, por lo común, fuera de la atmósfera del delito. Distinto para cada país. . . recibiendo en Francia el nombre de argot, el 
de gergo en Italia, en España el de bribia, germanía, hampa o caló y el de lunfardo en la República Argentina." (Dellepiane, 1894, p. 8).

Los críticos a la inmigración en Argentina a fines del siglo XIX, particularmente los de la alta sociedad, afirmaron que la creciente criminalidad era en gran parte debido al incontrolado desembarco de inmigrantes con prontuario criminal, especialmente aquéllos del sur de Europa (Castro, 2006, p. 95). Un Jefe de la Policía explica este sentimiento contra la inmigración de la siguiente manera:

(9) "Buenos Aires, lo mismo que toda la República -abierta de par en par a quien quiere venir a ella- recibe por fuerza, dentro de la corriente inmigratoria normal, buena parte de la escoria antisocial de los demás países." (Gómez, 1908, p. 30).

Para Gómez, este componente extranjero se apropió del lenguaje de los inmigrantes, entre los que el lunfardo no pasó desapercibido:

(10) "Es de advertir que la mayoría de las voces que constituyen la jerga de nuestros delincuentes, derivan de la de otros países." (Gómez, 1908, p. 110).

\section{El lunfardo}

El lunfardo comparte con otros argots las bases sociales que dan lugar a este tipo de lenguaje. Las primeras descripciones refieren directa o indirectamente al argot, jeringonza o jerga como categorías aplicables al lunfardo.

(11) "[...] un lenguaje secreto, utilizado por mendigos y ladrones en Francia medieval. En términos más amplios, argot puede referirse a cualquier vocabulario especializado o juego de palabras (jerga) utilizado por un determinado grupo social, por ejemplo, el argot de los jugadores o el argot del hampa." (Task, 2007, p. 85)ํ.

Esta caracterización del argot se asemeja a la referencia de Dellepiane sobre el lunfardo como un tecnicismo profesional, es decir, un lenguaje especial, cuyas características reflejan la base lingüística y la identidad de grupo compartidas por una comunidad de personas con intereses comunes (abogados, científicos, jóvenes, fans del deporte, jugadores, etc.):

1 Las cursivas son mías. 
(12) “Así, al ladrón -y solamente al ladrón- puede ocurrírsele dar un nombre especial a cada uno de los bolsillos del traje masculino; en lo cual nuestro argot aventaja a la misma lengua ordinaria que no ha pensado jamás en establecer semejantes distinciones ('cabalete', bolsillo en general; 'grillo', bolsillo lateral del pantalón; 'grillo de espiante', bolsillo trasero del pantalón; 'grillo de camisulín', bolsillo del chaleco [...]." (Dellepiane, 1888, p. 1617).

En Los hombres de presa, Drago nos traslada más allá de la explicación un tanto impresionista que Lugones tiene del lunfardo, cuya función está principalmente limitada a la de un lenguaje secreto o cripto-idioma. El uso que hace Drago de la frase modo peculiar de expresión -basada en el modelo sociológico del mundo del hampa de Lombroso (1875) - refuerza tanto a la identidad secreta y a la función grupal del lunfardo como a la variedad utilizada por personas que comparten la misma profesión, actividad o clase social:

(13) "En cuanto al empleo del argot, ese lenguaje a la vez pintoresco y cínico, destinado como lo dicen los mismos criminales, a ocultar sus comunicaciones a los extraños, puede muy bien ser, según apunta Lombroso, la reproducción del fenómeno en cuya virtud todos los gremios y oficios, como las diversas capas sociales, y aún los diferentes géneros de literatura, tiene sus modos peculiares de expresión." (Drago 1888, p. 1012).

A continuación, serán descritas algunas de las características semánticas, fonéticas, morfológicas y léxicas del lunfardo, con el objeto de demostrar que los mecanismos lingüísticos en su desarrollo no son muy diferentes a los que normalmente contribuyen a la formación de otros argots, una visión enunciada ya hace más de un siglo por Dellepiane:

(14) “Los modos principales de la formación de los términos de la jerga criminal son los tropos, las imágenes, las homofonías y asonancias, la onomatopeya, la reduplicación, los barbarismos y neologismos, los arcaísmos y la alteración fonética de voces del idioma ordinario." (1894, p. 55).

\subsection{Algunos rasgos lingüísticos del lunfardo}

Semántica: metáforas, metonimias y sinécdoques son parte del rico imaginario utilizado por los creadores del lunfardo: 
(15 ) madrastra 'cárcel', quinta 'cárcel', dátil 'ladrón', campana 'vigilante'.

Fonología: la homofonía, la modificación fonética y el simbolismo de sonidos tuvieron un rol en la formación del lunfardo (Conde 2011:341). (16) cumple 'cómplice' < 'cómplice' + 'cumplir'; ladrillo 'ladrón < 'ladrillo' + 'ladrón'; león 'pantalones' < 'pantalones' + 'león'.

Palabras lunfardas derivadas del italiano con grupo consonántico en posición inicial llevan epéntesis.

(17) espiantar 'fugar' < Ital. spiantare 'fugar'; escabiar 'beber en exceso' < Genovés scabbio 'vino'; esquiafo 'bofetada' < Ital. schiaffo'bofetada'.

Las consonantes dobles o geminadas italianas se simplificaron en el lunfardo, aunque seguramente eran pronunciadas con asiduidad entre los delincuentes ítalohablantes. Si bien la ortografía no siempre es confiable en la pronunciación, es aún menos en lo que concierne a la representación de la duración consonántica, especialmente dada la falta de consistencia ortográfica entre los diversos autores.

(18) nono, nona 'abuelo/a' < Ital. nonno, nonna 'abuelo/a'; chitrulo 'estúpido' < Ital. citrul lo 'estúpido'; cazote 'golpe' < Ital. cazzotto 'golpe'.

Morfología: Los ejemplos (19-20) cubren un rango de transformaciones morfológicas que conforman el lunfardo, varias de las cuales pueden ser atribuidas al entrecruce de influencias lingüísticas. Así, el recorte o abreviatura de palabras extensas puede ir seguido de lexicalización:

(19) tano 'italiano' < 'napolitano '; corte 'instrumento cortante' < 'cortafierro; sario 'comisario' < 'comisario'.

La afijación o uso de afijos derivados de un término lunfardo para derivar otra palabra lunfarda, emparentada por su significado se ve en (20):

(20) marroquería 'panadería' < Lunf. marroque 'pan' < Caló marró 'pan'. encanar 'arrestar, poner en prisión' < Lunf. cana 'prisión'. guitero 'recaudador de dinero robado < Lunf. guita 'dinero'.

La reduplicación también contribuye en la formación de vocablos lunfardos: 
(21) bobo 'reloj de cadena', bibı'mujer', tun tun 'revólver' (Gobello,1982, p. 32).

La metátesis -permutación de sonidos o de sílabas dentro de una misma palabra- no se encuentra en el corpus del lunfardo aquí analizado, En el español popular porteño, "vesre" es el término otorgado a la inversión -regular e irregular- del orden de las sílabas en palabras polisilábicas, por ej. re-vés > vesre. Puede o no existir extensión semántica consecuencia de la metátesis en el lunfardo.

(22) Lunf. garpar <'pagar' + Lunf. garpe 'pago' (Gobello, 1982, p. 96).

\section{Una comparación léxica del corpus lunfardo (18791908)}

La naturaleza del léxico lunfardo seleccionado para este estudio está determinada por la intención y la extensión de cada una de las fuentes, las cuales se describen a continuación.

(a) Las 128 páginas de la monografía de Dellepiane (1894) acerca del hampa de Buenos Aires contiene un diccionario lunfardoespañol de 428 vocablos y 182 frases, muchas más que las mencionadas por las otras cuatro fuentes. Sesenta de esas palabras ya habían sido incluidas por Lugones (1879); por lo tanto Dellepiane agregó 368 nuevos términos (Conde, 2011, p. 8990).

(b) Debido a su naturaleza periodística, los dos artículos de Lugones (1879 ab) son necesariamente limitados en extensión. Aun así, las 78 palabras lunfardas incluidas en ellos, junto a los doce términos publicados anónimamente un año antes en La Prensa, es históricamente significativo, ya que ellos se ubican entre los más tempranos ítems lexicales registrados en dicha lengua. $\mathrm{Ni}$ las dieciocho palabras mencionadas en Lugones ni los doce términos en La Prensa aparecen en el diccionario lunfardoespañol de Dellepiane. En la sección 4.0 se explicará que la difusión lexical pudo ser la causa de esta disparidad, ya que en 1879 el lunfardo había comenzado a ingresar en el español popular porteño una década más tarde.

(c) Los ensayos de Álvarez no describen la composición lexical del lunfardo con la minuciosidad de Dellepiane. El hecho de que él escribiera sus memorias en 1897, varios años después de abandonar 
la Fuerza Policial, puede explicar la poca extensión del listado de Álvarez, de sólo treinta y tres palabras. No obstante, esa escasez en las Memorias de un policía la compensa el grado de interés etnográfico puesto por el autor en la Buenos Aires clandestina.

(d) Drago (1888) registra treinta y cuatro términos lunfardos; no demasiados, en vista del hecho que Los hombres de presa tiene una extensión de 285 páginas. De éstas, ocho palabras no habían sido previamente mencionadas ni en Lugones ni en el artículo anónimo de La Prensa (Conde, 2011, p. 89).

(e) Finalmente, Gómez (1908) -la última de las fuentes del lunfardo incluida en este análisis- contiene un total de sesenta y cuatro palabras, muchas ya aparecidas en las referencias anteriores.

La Tabla 1 enumera el vocabulario compartido entre Dellepiane y Lugones, Drago, Álvarez y Gómez, respectivamente. Dellepiane sirve de referente, ya que aporta el léxico lunfardo más extenso compilado a lo largo del período en estudio.

Tabla 1.

Vocabulario lunfardo en las cinco fuentes del corpus.

\begin{tabular}{llllll}
\hline & Lugones & Drago & Dellepiane & Álvarez & Gómez \\
\cline { 2 - 6 } & $(1879)$ & $(1888)$ & $(1894)$ & $(1897)$ & $(1908)$ \\
\hline $\begin{array}{l}\text { total de palabras } \rightarrow \\
\text { palabras compartidas }\end{array}$ & 78 & 34 & 428 & 33 & 64 \\
\hline con Dellepiane $\rightarrow$ & 60 & 33 & & 15 & 40 \\
\hline porcentaje compartido & $85 \%$ & $97 \%$ & $100 \%$ & $45 \%$ & $63 \%$ \\
\hline
\end{tabular}

Toda tendencia basada en estas cifras debe ser interpretada con cautela. Drago comparte casi la totalidad de su vocabulario con Dellepiane (97\%), mientras que las otras cuatro fuentes registran desde un $45 \%$ a un $85 \%$ del léxico lunfardo. Una comparación entre la primera (Lugones) y la última fuente (Gómez) arroja veintitrés términos en común (36\%). Las veintisiete palabras confirmadas en Lugones pero no en Gómez, incluyen algunas que han perdido su condición lunfarda tras difundirse en el español popular porteño, por ej. atorrar 'dormir', escrachar 'derribar por la fuerza' y guita 'dinero' (Gobello, 1982). Asimismo, hay términos lunfardos en Lugones no hallados en Gómez, que parecen no haber pasado al español 
popular porteño, por ej. cala 'porte' y brema 'juego de naipes'. Las cifras indicadas más arriba son proporcionadas principalmente para subrayar el fenómeno de difusión a través de sociolectos durante el período 18901930, de alta movilidad social y crecimiento de la clase media argentina (Germani, 1955, p. 219).

\section{La contribución de las lenguas de inmigrantes al lunfardo}

El número de inmigrantes europeos -especialmente italianos y españoles- que desembarcaron en el puerto de Buenos Aires creció a tal ritmo que, para el centenario de la Independencia argentina en 1910, la mitad de la población urbana era extranjera (Scobie, 1974). Entre ellos había inmigrantes que se habían 'desviado' de la senda del trabajo arduo y del sacrificio eligiendo, en cambio, el sendero de la mala vida. Para la policía, los delincuentes extranjeros eran particularmente más peligrosos que los criollos, requiriendo de este modo una vigilancia más cuidada:

(23) "Buenos Aires encierra dos clases de pícaros: los naturales y los extranjeros. Los primeros son pocos, relativamente, y menos peligrosos que los segundos. El pillo extranjero es el más abundante." (Álvarez, 1897, p. 52).

Italia contribuyó significativamente a la vida del bajo mundo, lo que no es una sorpresa, dado su importante aporte al total de inmigrantes:

(24) “Los escruchantes más terribles son los italianos, que están constituidos en pequeñas asociaciones de mutua protección [...]" (Lugones, marzo 18, 1879).

Entre las regiones de origen de los inmigrantes, muchas se organizaban en asociaciones de mutua protección, siendo las más visibles las que contribuyeron al aumento poblacional: Génova, Calabria, Piamonte, Lombardía, Sicilia, Venecia y Nápoles (en Italia), y Galicia y Asturias (en España). En el corpus estudiado se incluyen términos para describir la nacionalidad de los delincuentes inmigrantes (italianos, españoles y uruguayos). La presencia de italianos en las bandas criminales es lingüísticamente relevante y los propios argots dialectales, como el furbesco o gérgo de la mala vita, debieron de haber contribuido al surgimiento del lunfardo (Conde, 2011). 
Se torna difícil a la hora de distinguir los italianismos generales de los regionalismos en el lunfardo, en vista de la diversidad lingüística de Italia hacia la reunificación (1870), cuando la inmigración desde la Península hacia Argentina comenzó a tomar ímpetu. En la formación del vocabulario lunfardo, además de los italianismos deben tenerse en cuenta las contribuciones del argot francés, la germanía y el caló españoles y la giria de Brasil (Conde, 2011, p. 147ss.).

De las quinientas palabras del lunfardo que figuran en Lugones, Drago, Dellepiane, Álvarez y Gómez, aproximadamente la mitad es de origen italiano. Éstas derivan no sólo del italiano estándar -el cual a su vez está basado principalmente en el dialecto toscano-, sino que también se encontraron otras palabras del romano o romanesco así como otras variedades regionales y el propio gérgo o jerga del delito. Los genoveses tuvieron un rol especial entre los dialectos que contribuyeron al léxico del lunfardo. Por ej., más del 40\% (35/78) de las palabras presentadas en Lugones (1879ab) pertenecen al genovés original (Conde, 2011, p. 159). Ciertamente, la influencia de los inmigrantes genoveses en la transformación de la sociedad de Buenos Aires, entre 1880 y 1920, fue amplia, como así lo atestigua el antiguo barrio de La Boca conocido en aquel tiempo como "la pequeña Génova”.

Palabras del corpus lunfardo, existentes en el español popular porteño y cuyos orígenes pueden ser rastreados a las variedades regionales del italiano, son enumeradas a continuación:

(25)a. bacán 'hombre, jefe' < Genovés baccan 'jefe' (Gobello, 1982, p. 22).

b. encanar 'arrestar, poner en prisión' + Lunf. cana 'prisión' < Veneciano incaenar 'encadenar' (Gobello, 1982, p.77).

\subsection{El cocoliche}

El alto número de inmigrantes italianos en Argentina en relación a otras nacionalidades entre 1870 y 1930, y cierta permisividad en el cumplimiento de las leyes inmigratorias contribuyeron al mayor peso de los italianismos en el léxico lunfardo (ver Gómez, cita anterior). Así, no sorprende que el español popular porteño muestre un significativo número de términos italianos en comparación con otros dialectos latinoamericanos (Meo-Zilio, 1930). 
Para comprender la difusión lexical desde el lunfardo hacia el español popular porteño, es fundamental considerar las características del español hablado por inmigrantes italianos, popularmente conocido como cocoliche. Esta adquisición natural, transitoria e imperfecta del español por los inmigrantes italianos pudo haber favorecido la difusión de rasgos lingüísticos (no solamente léxico) entre los habitantes de los conventillos donde ellos convivían con inmigrantes de otros orígenes. El conventillo se caracteriza por ser una "[...] vivienda urbana con un gran número de habitaciones en cada una de las cuales vivían grupos humanos distintos, que hacían uso en común de los servicios sanitarios y aún de las cocinas" (Coluccio, 1994, Op. Cit. en de la Torre 2008, p. 41). Vinculado al conventillo, el sainete, género literario popular, a menudo representó en el escenario la vida de inmigrantes y, asimismo, fue un vehículo para caracterizar al español imperfecto hablado por italianos, españoles, gallegos, judíos y otros grupos de inmigrantes en Argentina.

Sin embargo, el cocoliche de los italianos se transformó en el código lingüístico más fácilmente reconocido de los sainetes, cuyo español mostraba transferencias desde sus variedades del italiano. Por lo tanto, la pregunta retórica de Don Gaetano, E donde se produce la mescolanza? Al conventillo, en el sainete "Mustafá" cuando descubre que su hija quiere casarse con un inmigrante de Medio Oriente ('turco') expresa la percepción popular del conventillo como espacio propiciador del contacto entre inmigrantes, indiferente a la nacionalidad, religión o lengua de sus habitantes durante las primeras etapas de la aculturación del inmigrante al nuevo país.

El estudio panorámico de Reinecke (1937) sobre variedades resultantes del contacto lingüístico o 'marginal languages' (lenguas marginales) es un primer intento riguroso por caracterizar ese español italianizado como un habla mixta sin la gramática sistemática y el léxico estable propio del lenguaje criollo, por ej., el papiamento curazoleño o el chabacano filipino. Para Whinnom (1971) el cocoliche es el resultado de una segunda hibridación o adquisición de una segunda lengua imperfecta que abarca un espectro de lectos individuales, desde el italiano nativo al español no nativo de los inmigrantes. Aunque altamente variable se caracteriza el cocoliche, según Whinnom, por ser un sistema lingüístico más estable y predecible. Más aún, él distingue entre el estereotipado cocoliche del sainete y el cocoliche real tal como se demuestra en los usos 
erróneos de las partículas discursivas 'vi' y 'ne' del italiano en el popular sainete (ver también Cara-Walker, 1987; Golluscio de Montoya, 1981). Otros estudios del cocoliche (MeoZillio, 1970; Fontanella de Weinberg, 1987) que trataron sobre los contrastes sociolingüísticos en el uso del cocoliche, sostuvieron que los hombres usaban formas más hispanizadas que las mujeres, en tanto que los criollos comprendían mejor los lectos o variedades estilísticas menos italianizadas. Además, en el léxico del cocoliche se reflejaba la sociabilidad, espacios sociales y el mundo laboral por los que se desplazaban los inmigrantes. Finalmente, es importante destacar la variabilidad lingüística del cocoliche respecto a la distancia tipológica entre el español y el italiano, así como las diferencias entre dialectos italianos del norte (toscano, piamontés) y del sur (calabrés, siciliano).

\section{Discusión}

Los primeros testimonios periodísticos y monografías criminológicas popularizaron la exclusiva asociación del lunfardo con la comunicación del hampa. Innegablemente, el lunfardo ejerció un papel importante en el submundo marginal, tal como lo exponen Drago, Dellepiane y Gómez. No obstante, sostendremos que una interpretación más amplia del lunfardo hace posible una revaloración de dicho idioma al considerar tanto la historia sociolingüística de las lenguas de inmigrantes, en particular el italiano, así como los sociolectos populares del español. En efecto, el contacto lingüístico en los conventillos nos ayuda a entender con mayor claridad cómo se produjo el préstamo y la difusión lexicales que circularon en el espacio social conformado por los hablantes del español porteño y del lunfardo. Así, el arribo de italianos, españoles y otros inmigrantes tuvo su contraparte edilicia en la creación del puerto de Buenos Aires, la modernización y expansión del transporte (subterráneo, ferroviario, terrestre) y la construcción de populares viviendas para ubicar a los muchos inmigrantes (de la Torre 2008, p. 37; Walter, 1993, p. 19). Esto ocurría a la vez que las familias criollas acaudaladas comenzaban a mudarse a áreas residenciales ubicadas en el norte de la ciudad de Buenos Aires (barrio de Belgrano), menos expuestas a las enfermedades y otros males asociados a las masas humanas que irrumpieron en las zonas céntricas durante la inmigración. Sus residencias pasaron a ser los conventillos de los inmigrantes y argentinos de clase baja. 
Los censos nacionales de 1869, 1895 y 1914 arrojan la siguiente información sobre los conventillos porteños (Scobie, 1974, p. 264; Baer, 1994, p. 99):

- Cada conventillo tenía un promedio de sesenta inquilinos.

- En 1904, más de un cuarto de la población $(26,8 \%)$ de la ciudad de Buenos Aires vivía en conventillos.

- En 1895, las personas nacidas en Argentina que vivían en conventillos equivalían a casi la mitad de la población de inquilinos.

- Los extranjeros representaban a la mayoría de la población de inquilinos en los conventillos; entre los extranjeros, predominaban españoles e italianos.

En el conventillo era frecuente encontrar inmigrantes que provenían del mismo país o, incluso, región de origen, llevados a convivir con otros inmigrantes por razones de parentesco o amistad que facilitaban las redes sociales ya encontradas a su arribo en el país anfitrión (Baily y Ramella, 1988; Italiano, 2013). Tal fue el caso del conventillo sito en la calle San Martin 256/258, donde el 93 por ciento de los inquilinos eran italianos. Los inmigrantes mantenían vínculos con gente de su misma nacionalidad, pueblo o dialecto, especialmente apenas llegados a Buenos Aires con el objeto de encontrar trabajo y vivienda. Además, la clase social contribuyó a la cohesión entre inmigrantes, demostrado, por ejemplo, en las reivindicaciones por la mejora en las condiciones sanitarias de los conventillos y el control del precio de alquileres durante las cuales inquilinos (argentinos e inmigrantes) se enfrentaban a los propietarios, tal como ocurrió con la huelga de inquilinos de 1907 (Páez, 1970).

Durante los primeros años de residencia en el país, los inmigrantes encontraban más oportunidades para aprender español. El siguiente testimonio de un joven italiano alude al extendido uso de dialectos italianos en Buenos Aires, a la par del italiano estándar.

(26) “El idioma aquí es castellano... pero no oigo a nadie hablarlo. Dondequiera que uno vaya, en el hotel o en el trabajo, todos hablan piamontés o italiano, aun los que son de otros países y, hasta los argentinos hablan italiano." (Baily y Ramella, 1988, p. 1645).

El impacto de la socialización en el mayor uso del español era en parte consecuencia de la afinidad cultural entre Argentina e Italia, que 
facilitaron sobre todo la rápida asimilación de los hijos de inmigrantes (Payol, 2000, p. 142). La experiencia del conventillo como micro-espacio del contacto lingüístico fue más intensa entre 1880 y 1930, dando paso luego a otros factores como los matrimonios internacionales entre hijos de inmigrantes, la educación, la industrialización, la urbanización y el acceso al propio hogar. Todo ello sustentó la movilidad social que elevó a un significativo porcentaje de inmigrantes a sectores medios de la estructura social (Germani, 1955, p. 22; Fontanella de Weinberg, 1987, p. 141).

Siendo el idioma oficial de Argentina, el español propició una fuerza unificadora para la inmigración a través de tres procesos: (1) sistema libre, gratuito y laico de enseñanza, fundado en la Ley No 1420, (2) alfabetización y (3) creciente sentimiento nacionalista (Walter, 1993, p. 15; Torre, 2010, p. 177).

Las relaciones entre inmigrantes y criollos en el conventillo debió de tener un rol fundamental en la incorporación de léxico itálico (italiano, dialectal) en el español popular porteño. Por otro lado, los factores sociales, económicos y políticos delineados previamente favorecieron en el lapso de una o dos generaciones el desplazamiento del italiano por el español argentino sin las interferencias estructurales (morfológicas, sintácticas) que son propias de otras situaciones de contacto intenso con mudanza lingüística intergeneracional (Thomason y Kaufman, 1988).

El uso del cocoliche, o español imperfecto, hablado por los inmigrantes italianos ayudó seguramente a la comunicación entre inmigrantes y argentinos, facilitando la entrada de elementos españoles e italianos en dos variedades de ese lenguaje imperfecto: (1) el cocoliche real, resultado de la transferencia de italianismos al español por parte de los inmigrantes italianos y (2) el cocoliche folklórico, surgido del intento por parte de los argentinos de imitar el habla de los inmigrantes italianos, muchos estereotipados en los sainetes de época. Más allá del peso relativo de las dos vías de difusión lexical, el resultado final fue la introducción de italianismos y pseudo-italianismos en el español porteño emergente durante las décadas de mayor inmigración, tal como lo atestigua todavía su elevado número en la actual variedad porteña.

El lunfardo no fue inmune a ese doble canal de difusión entre las hablas inmigrantes y el español porteño, ya que los varios tipos de criminales que se describen en la sección 2.0 (punguistas, biabistas y 
escruchantes) convivieron en los conventillos con criollos e inmigrantes de distintas nacionalidades. Así lo evidencia el hecho de que, mientras el lunfardo utilizado en los sainetes escritos antes de 1890 era frecuentemente traducido, no ocurría lo mismo con los más tardíos, lo que se puede explicar a partir de la difusión de elementos lunfardos al español porteño general (Castro, 2006, p. 106). Esta difusión, seguramente, fue selectiva en la admisión de unos y no otros vocablos lunfardos, como deducimos de un artículo aparecido en el diario $\mathrm{La}$ Nación (11 de febrero de 1887) llamado "Caló porteño". En el mismo, el autor hace referencia a un "Diccionario de argentinismos", una clara referencia a las palabras de gran circulación entre las clases sociales más bajas de Buenos Aires.

Desde el momento que una parte importante del vocabulario en el corpus analizado en la sección 3.0 están presentes en el artículo de 1887, se abre la posibilidad que Lugones, Drago y los otros autores atribuyeran al lunfardo palabras que no fueran de uso exclusivo de los delincuentes. Es posible que hayan creído que el vocabulario supuestamente secreto empleado por criminales en prisión era exclusivamente lunfardo, sin reparar en que varios de esos vocablos formaban ya parte del repertorio lexical del español popular porteño. También no se debe descartar que en ese lapso de ocho años entre la publicación de Lugones (1879ab) y el "Caló Porteño" de 1887, varios términos lunfardos se encuentren actualmente difundidos en el español porteño. En este aspecto, sería conveniente diferenciar entre términos "técnicos" asociados a la existencia del lunfardo (bobo "reloj", shua "llave") y otros vinculados a los sociolectos del habla popular (atorrante 'holgazán', morfar 'comer') (Conde, 2011, p. 97). Sea o no que la totalidad o parte del vocabulario lunfardo se haya originado en el hampa, la difusión del léxico continuó avanzando irreversiblemente en la sociedad.

Hacia los años '30, las expresiones de la cultura popular -como el tango y el sainete-colaboraron para propagar el uso de palabras que eran originalmente restringidas a los sociolectos bajos del español argentino, al lunfardo y al cocoliche, y luego filtrándose a los estratos sociales más altos. De este modo, una rápida comparación muestra que, de los quinientos términos lunfardos iniciales que constituyen el corpus sobre el cual está basado este trabajo, noventa todavía perviven en el español popular porteño. Asimismo, un lunfardismo en un doblete semántico 
con una palabra en el español estándar expresa, además de matices semánticos, la identidad, edad o circunstancias sociales del hablante, por ej: comer vs. 'morfar' (comer en exceso) y dormir vs. 'apoliyar"' (despertar tardíamente).

\section{Conclusión}

La inmigración a la Argentina creó las condiciones sociales de marginalidad (delincuencia, criminalidad) para la aparición del lunfardo o jerga especial de los ladrones, el cual, una vez difundido a toda la sociedad, recorrió los mismos cambios semánticos que afectan el vocabulario de toda lengua de uso general, tal como lo ejemplifica la pérdida de la asociación restrictiva a la vida del hampa en el vocabulario del corpus. Esta variedad "descriminalizada" del lunfardo devino -junto a los italianismos del cocoliche- en un componente del español porteño del presente. Con el tiempo, el lunfardo fue superando las estructuras y fronteras sociales impuestas por la sociedad clasista, convirtiéndose en la vertiente incondicional, niveladora e identitataria del habla de los argentinos y, como la cenicienta de la comunicación, forma parte de la literatura de autores canónicos argentinos como Robert Arlt, Julio Cortázar y Jorge Luis Borges. Un fiel indicador de la valoración e influencia del lunfardo en el lenguaje argentino es la existencia de la Academia Porteña del Lunfardo, que celebra todos los 5 de septiembre el Día del Lunfardo. 


\section{Referencias Bibliográficas}

Álvarez, J. (1897). Memorias de un vigilante. Buenos Aires: Vaccaro.

Baer, J. A. (1994). Street, block, and neighborhood: residency patterns, community networks, and the 1895 Argentine manuscript census. The Americas, 51, 89101.

Baily, S. (Ed.), Ramella, F. (Ed.). (1988). One family, two worlds. New Brunswick: Rutgers University Press.

CaraWalker, A. (1987). Cocoliche: The Art of Assimilation and Dissimulation among Italians and Argentines. Latin American Research Review, 22, 3767.

Castro, D. S. (2006). The Image of the Creole Criminal in Argentine Popular Culture: 18801930. Studies in Latin American Popular Culture, 25, 95117.

Coluccio, F. (1994). Diccionario de voces y expresiones argentinas. Buenos Aires: Plus Ultra.

Conde, O. (2011). Lunfardo, un estudio sobre el habla popular de los argentinos. Buenos Aires: Aguilar.

Dellepiane, A. (1894). El idioma del delito. Buenos Aires: Fabril Editora.

Drago, L. M. (1888). Los hombres de presa. Buenos Aires: Félix Lajouane Editor.

Fontanella de Weinberg, M. B. (1987). El español bonaerense: cuatro siglos de evolución lingüística (15801980). Buenos Aires: Hachette.

Gayol, S. (2000). Sociabilidad en Buenos Aires: hombres, honor y cafés, 18621910. Buenos Aires: Ediciones del Signo.

Germani, G. (1955). Estructura social de la Argentina. Análisis estadístico. Buenos Aires: Editorial Raigal.

Gobello, J. (1982). Diccionario lunfardo. Buenos Aires: Peña Lillo Editor.

Golluscio de Montoya, E. (1981). Grotesco rioplatense y convención cocolichesca (Stefano, de Armando Discépolo). Letterature d'America, 2, 135153. 
Gómez, E. (1908). La mala vida en Buenos Aires. Buenos Aires: Editor Juan Roldán.

Italiano, M. (2013). The linguistic experience of Italians in Buenos Aires, 1890194: language shift as seen through social spaces (tesis doctoral), Temple University.

Lombroso, C. (1876). L'uomo delinquente. Torino: Fratelli Bocca.

Lugones, B. (1879a). Los beduinos policiales. Marzo 18, 1879. La Nación.

Lugones, B. (1879b). Los caballeros de la industria. Abril 6, 1879. La Nación.

MeoZilio, G. (1970). El elemento italiano en el habla de Buenos Aires y Montevideo. Florencia: Valmartina Editore.

Páez, J. (1970). El conventillo. Buenos Aires: Centro Editor de América Latina.

Reinecke, J. E. (1937). Marginal languages: a sociological survey of the creole languages and trade jargons (tesis doctoral), Yale University.

Scobie, J. R. (1974). Buenos Aires: Plaza to Suburb, 1870-1910. New York: Oxford University Press.

Task, R. L. (2007). Language and linguistics: The Key Concepts. New York: Routledge

Thomason, S. G., Kaufman, T. (1988). Language contact, creolization, and genetic linguistics. Berkeley: University of California Press.

Torre, J. C. Transformaciones de la sociedad argentina. En Roberto Russell (Ed.), Argentina 1910-2010. Balance del siglo (167-225). Buenos Aires: Taurus.

Torre, L. de la. (2008). Buenos Aires: del conventillo a la villa miseria (18691989). Buenos Aires: Editorial de la Universidad Católica Argentina.

Walter, R. J. (1993). Politics and urban growth in Buenos Aires, 1910-1942. Cambridge: Cambridge UP. 
Whinnom, K. (1971). Linguistic hybridization and the 'special case' of pidgins and creoles. En Hymes, D. (Ed.), Pidginization and Creolization of Languages (pp. 91115). Cambridge: Cambridge University Press. 